\title{
UPAYA PENINGKATAN PENGETAHUAN KADER SANTRI HUSADA POSKESTREN AL HIKAM BANGKALAN TENTANG KESEHATAN REPRODUKSI REMAJA
}

\author{
Tri Wahyuni Bintarti' ${ }^{1)}$, Handayani ${ }^{2)}$; Rizqi Putri Nourma Budiarti³), Dewi Masithah ${ }^{4}$ \\ 1,2,3,4) Universitas Nahdlatul Ulama Surabaya \\ e-mail: bintarti_tri@unusa.ac.id ${ }^{1)}$,handayani@unusa.ac.id ${ }^{2}$, \\ rizqi.putri.nb@unusa.ac.id ${ }^{3)}$,dewi.masithah@unusa.ac.id ${ }^{4)}$
}

\begin{abstract}
Abstrak
Pondok Pesantren Al Hikam Bangkalan memiliki POSKESTREN dan Kader Santri Husada yang terdiri atas santri berusia SMP dan SMA. Pondok pesantren Al Hikam Bangkalan memiliki dua asrama besar untuk putra dan putri. Kedua asrama ini masih dalam satu area dan berdekatan. Ketertarikan dengan lawan jenis pada usia remaja masih harus dengan bimbingan orang tua. Perlu diketahui bahwa tingkat aborsi di kalangan remaja diperkirakan sekitar 700 ribu kasus per tahun atau sekitar 30 persen dari seluruh kasus aborsi per tahun di Indonesia (Hidayangsih, 2014). Penyuluhan tentang kesehatan reproduksi remaja dilakukan agar remaja di AlHikam Bangkalan memiliki wawasan tentang pentingnya menjaga kesehatan reproduksi di usia remaja. Penyuluhan berlangsung secara tertib dengan jumlah peserta sebanyak 50 orang dari kader santri husada poskestren pondok pesantren Al Hikam Bangkalan. Kegiatan ini cukup mendapatkan perhatian dan antusias dari santri, hal ini terlihat dengan jumlah peserta dan keaktifan diskusi saat penyuluhan berlangsung. Kegiatan penyuluhan ini juga menunjukkan adanya peningkatan pengetahuan pada kader santri husada poskestren pondok pesantren Al Hikam Bangkalan. Hal ini di tunjukkan dengan hasil peningkatan post-test lebih tinggi dari hasil pre-test.
\end{abstract}

Kata Kunci : Santri Husada Poskestren, Kesehatan Reproduksi, Al Hikam Bangkalan.

\section{PENDAHULUAN}

Menurut WHO, remaja adalah penduduk dalam rentang usia 10 - 19 tahun. Sedangkan menurut peraturan menteri kesehatan RI nomor 25 tahun 2014, remaja adalah penduduk dalam rentang usia $10-18$ tahun. Dan menurut Badan Kependudukan dan Keluarga Berencana Nasional (BKKBN) rentang usia remaja adalah 10 - 24 tahun dan belum menikah. Jumlah kelompok usia 10 -19 tahun di Indonesia menurut sensus penduduk 2010, sebanyak 43,5 juta atau sekitar $18 \%$ dari jumlah penduduk. (Kementerian Kesehatan RI, 2017)

Saat ini, Indonesia telah memasuki era Bonus Demografi sampai 2035. Bonus Demografi merupakan salah satu perubahan dinamika demografi yang terjadi karena adanya perubahan struktur penduduk menurut umur dimana jumlah penduduk usia produktif lebih banyak dari penduduk usia non produktif (Yusmarni, 2016). Hal ini dapat menjadi keuntungan Indonesia untuk memberdayakan masyarakatnya dengan baik. Namun hal ini menjadi berbahaya apabila penduduk usia remaja kita terjerumus ke dalam pergaulan bebas yang dapat merusak mental remaja kita.

Masa remaja merupakan masa transisi antara masa kanak-kanak dengan dewasa. Remaja pada tahap ini belum mencapai kematangan mental dan sosial sehingga remaja harus menghadapi banyak tekanan emosi dan sosial yang saling bertentangan. Remaja akan mengalami perubahan fisik yang cepat ketika remaja memasuki masa puber. Salah satu dari perubahan fisik tersebut adalah kemampuan untuk melakukan proses reproduksi. Tetapi banyak fenomena memperlihatkan sebagian remaja belum mengetahui dan memahami tentang kesehatan reproduksi, misalnya tentang menstruasi dan terjadinya kehamilan (Ernawati, 2018).

Pemahaman dan pengetahuan remaja terhadap kesehatan reproduksi dan seksualitas selama ini terbilang masih rendah dan tidak sedikit pula yang mengabaikannya. Hal ini dapat berimplikasi pada risiko seksual yang dihadapi oleh remaja. Pemahaman terhadap seksualitas dan kesehatan reproduksi yang diberikan di lembaga pendidikan formal maupun informal cenderung memandang aspek kesehatan reproduksi dan seksualitas remaja hanya sebatas pada fenomena biologis sematacenderung mengkonstruksikan seksualitas remaja sebagai hal yang tabu dan berbahaya-dikontrol melalui wacana moral, dan agama. Selain itu, agar lebih efektif, pemahaman terhadap seksualitas dan kesehatan reproduksi perlu dikon tekstualisasikan 
berdasarkan realitas dan kondisi remaja (Miswanto, 2014).

Pondok Pesantren Al Hikam Bangkalan merupakan pondok besar dengan santri kurang lebih 2000. Pondok Pesantren Al Hikam Bangkalan memiliki POSKESTREN dan Kader Santri Husada yang terdiri atas santri berusia SMP dan SMA. Kader Santri Husada adalah anggota dari struktur kepengurusan POSKESTREN yang nantinya akan bertanggung jawab untuk kesehatan pondok pesantren terutama dalam hal preventif dan promotif.

Pondok pesantren Al Hikam Bangkalan memiliki dua asrama besar untuk putra dan putri yang terpisah. Namun meski pondok pesantren al hikam bangkalan memiliki asrama putri dan asrama putra terpisah, kedua asrama ini masih dalam satu area dan berdekatan. Ketertarikan dengan lawan jenis pada usia remaja masih harus dengan bimbingan orang tua. Seperti saat sekarang ini, pacaran mungkin adalah hal yang lumrah bagi kalangan remaja. Namun pacaran dapat membahayakan kesehatan reproduksi remaja tertutama jika sampai terjadi kehamilan di luar pernikahan dan aborsi.

Perlu diketahui bahwa tingkat aborsi di kalangan remaja diperkirakan sekitar 700 ribu kasus per tahun atau sekitar 30 persen dari seluruh kasus aborsi per tahun di Indonesia. Sehingga kondisi perilaku berisiko remaja Indonesia saat ini sungguh menunjukkan gejala yang makin mengkhawatirkan (Hidayangsih, 2014). Oleh karena itu diperlukan penyuluhan tentang kesehatan reproduksi remaja agar remaja di Al-Hikam Bangkalan memiliki wawasan tentang pentingnya menjaga kesehatan reproduksi di usia remaja.

\section{METODE KEGIATAN}

\subsection{Waktu dan Tempat Pelaksanaan}

Kegiatan pengabdian kepada masyarakat ini diselenggarakan di Pondok Pesantren Al Hikam Bangkalan. Program ini dilaksanakan selama 8 bulan dimulai dari persiapan hingga pelaporan

\subsection{Sasaran Peserta}

Sasaran peserta adalah 50 santri husada Poskestren Al Hikam Bangkalan yang dipilih secara acak dari berbagai jenjang usia dan pendidikan (SMA, SMK dan SMP).

\subsection{Tahapan Pelaksanaan}

\subsubsection{Persiapan}

Pada tahap persiapan dilakukan antara lain, persiapan internal tim, survey lapangan serta permohonan izin kepada pihak pondok pesantren. Persiapan internal tim menyangkut pembuatan materi penyuluhan, soal pre-test dan post test serta persiapan kebutuhan sarana prasarana untuk kegiatan. Survey lapangan dilakukan untuk melakukan perizinan sekaligus serta untuk mengetahui lokasi dan kondisi di pondok pesantren.

\subsubsection{Pelaksanaan}

Kegiatan inti adalah pelaksanaan pengabdian kepada masyarakat yaitu dengan penyuluhan tentang kesehatan reproduksi remaja kepada seluruh kader santri husada poskestren $\mathrm{Al}$ Hikam Bangkalan. Sebelum diberikan penyuluhan, santri diberikan pretest beberapa soal untuk mengetahui tingkat pengetahuan santri tentang kesehatan reproduksi remaja. Kemudian setelah diberikan penyuluhan santri juga diberikan posttest dengan soal yang sama untuk mengetahui tingkat pengetahuan santri tentang kesehatan reproduksi remaja setelah diberikan penyuluhan.
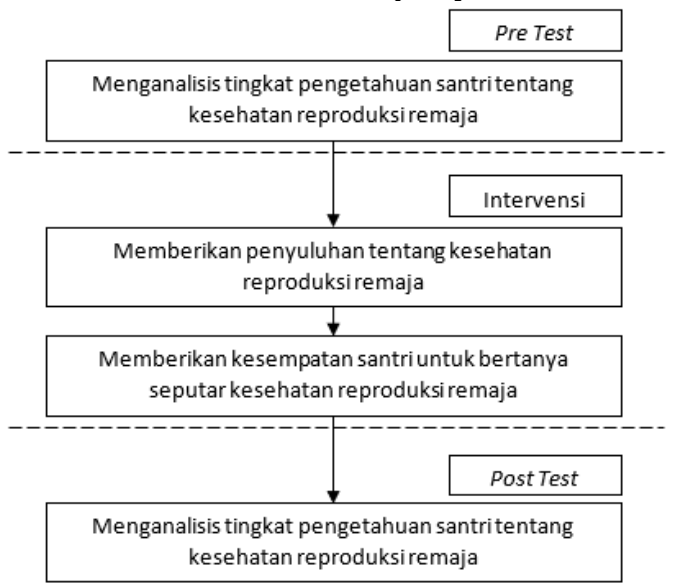

Gambar 2.1 Kerangka Operasional Pelaksanaan Penyuluhan Kesehatan Reproduksi Remaja Santri Husada Poskestren AlHikam Bangkalan

\subsubsection{Evaluasi}

Tahap evaluasi merupakan tahap untuk menganalisis tingkat pengetahuan santri tentang kesehatan reproduksi remaja sebelum diberikan penyuluhan dan sesudah diberikan penyuluhan melalui jumlah jawaban benar hasil pre-test dan post-test. 


\section{HASIL DAN PEMBAHASAN}

Kegiatan pengabdian kepada masyarakat ini dilakukan untuk mengedukasi santri agar memiliki wawasan tentang pentingnya menjaga kesehatan reproduksi di usia remaja. Pada saat kegiatan survey dilakukan penyebaran kuesioner. Kuesioner disebarkan pada santri dengan rentang usia $12-18$ Tahun dengan jumlah laki laki 22 orang dan perempuan 16 orang. Hasil survey berdasarkan kuesioner adalah seperti berikut :

Tabel 3.1 Hasil Survey Berdasarkan Kuesioner

\begin{tabular}{|l|l|c|c|c|}
\hline \multirow{2}{*}{ No } & \multicolumn{1}{|c|}{ Pertanyaan } & \multicolumn{3}{|c|}{ Hasil Survey (Orang) } \\
\cline { 3 - 5 } 1 & Memiliki teman dekat / pacar & 15 & 22 & 38 \\
\hline 2 & Memiliki ketertarikan dengan sesama jenis & 7 & 31 & 38 \\
\hline 3 & Mengetahui tentang penyakit menular seksual & 6 & 32 & 38 \\
\hline 4 & $\begin{array}{l}\text { Mengetahui cara penularan penyakit menular } \\
\text { seksual }\end{array}$ & 10 & 28 & 38 \\
\hline
\end{tabular}

Kegiatan berikutnya adalah penyuluhan kesehatan reproduksi remaja, kegiatan ini berlangsung secara tertib dengan jumlah peserta sebanyak 50 orang yang berasal dari kader santri husada poskestren pondok pesantren Al Hikam Bangkalan. Kader santri husada poskestren pondok pesantren Al Hikam Bangkalan terdiri atas santri dengan rentang usia 12 - 18 Tahun. Kegiatan ini cukup mendapatkan perhatian dan antusias dari santri, hal ini terlihat dengan jumlah peserta dan keaktifan diskusi saat penyuluhan berlangsung.

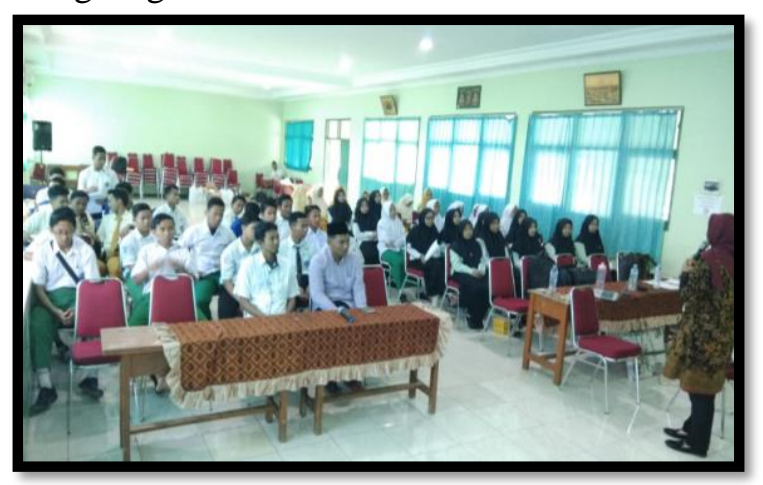

Gambar 3.1 Pelaksanaan Kegiatan Penyuluhan Kesehatan Reproduksi Remaja Santri Husada Pondok Pesantren Al Hikam Bangkalan

Sebelum dilakukan pemaparan materi dilakukan terlebih dahulu pre test dan setelah pemaparan materi, santri husada kemudian diberikan post-test. Kemudian analisis dilakukan dengan menghitung jumlah benar dari soal pre test dan post test. Berikut merupakan hasil rerata jumlah benar soal dari pre-test dan post-test.

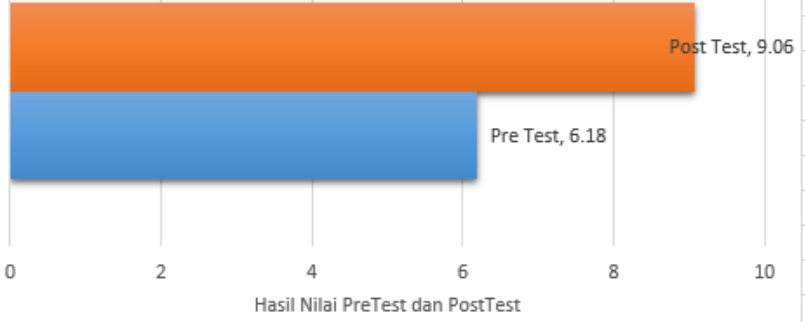

Gambar 3.1 Hasil Rerata Pre Test Dan Post Test

Dari hasil rerata jumlah benar soal pre test dan post test didapatkan bahwa hasil rerata jumlah benar post test lebih tinggi dari hasil rerata jumlah benar pre-test. Hal ini menunjukkan bahwa dengan penyuluhan materi tentang kesehatan reproduksi dapat memberikan pengetahuan atau wawasan tentang kesehatan reproduksi kepada seluruh santri husada di pondok pesantren Al-Hikam Bangkalan.

\section{KESIMPULAN}

Upaya peningkatan pengetahuan tentang kesehatan reproduksi remaja pada kader santri husada poskestren pondok pesantren Al Hikam Bangkalan dilakukan melalui kegiatan penyuluhan dengan materi Kesehatan Reproduksi Remaja. Kegiatan penyyuluhan ini menunjukkan bahwa pengetahuan kader santri husada poskestren pondok pesantren $\mathrm{Al}$ Hikam Bangkalan meningkat. Peningkatan pengetahuan kader santri husada di tunjukkan dengan hasil peningkatan post-test lebih tinggi dari hasil pretest.

\section{REFERENSI}

Ernawati, H. (2018) 'Pengetahuan Kesehatan Reproduksi Remaja Di Daerah Pedesaan', Indonesian Journal for Health Sciences, 2(1), pp. 58-64. doi: 10.24269/ijhs.v2i1.2018.pp5864.

Hidayangsih, P. S. (2014) 'Perilaku Berisiko Dan Permasalahan Kesehatan Reproduksi Pada Remaja', Pusat Teknologi Intervensi Kesehatan Masyarakat Badan LitBangKes, Kementrian Kesehatan, 5(2), pp. 1-10. doi: 10.22435/KESPRO.V5I2.3886.89-101.

Kementerian Kesehatan RI (2017) 'Infodatin Reproduksi Remaja-Ed.Pdf', Situasi Kesehatan Reproduksi Remaja, pp. 1-8.

Miswanto (2014) Pentingnya Pendidikan Kesehatan Reproduksi dan Seksualitas Pada Remaja, Studi Pemuda.

Yusmarni, . (2016) 'Analisis Bonus Demografi Sebagai Kesempatan Dalam Mengoptimalkan Pembangunan Pertanian Di Sumatera Barat', Jurnal AGRISEP, 15(1), pp. 67-82. doi: 10.31186/jagrisep.15.1.67-82. 
